Favini, G., Simonetta, M., Sottocornola, M. \& Todeschini, R. (1982). J. Comput. Chem. 3, 178-184.

GafNer, G. \& Herbstein, F. H. (1962). Acta Cryst. 15, 10811092.

GafNer, G. \& Herbstein, F. H. (1963). Nature (London), 200, $130-132$.

Gall, J. H., MacNicol, D. D., Mallinson, P. R. \& Welsh, P. A. (1985). Tetrahedron Lett. 26, 4005-4008.

Gerkin, R. E., Lundstedt, A. P. \& Reppart, W. J. (1984). Acta Cryst. C40, 1892-1894.

Hazell, A. C. (1978). Acta Cryst. B34, 466-471.

Herbstein, F. H. (1979). Acta Cryst. B35, 1661-1670.

Herbstein, F. H., Kapon, M. \& Merksamer, R. (1976). Acta Cryst. B32, 2205-2210.

Herbstein, F. H., Kapon, M. \& Rabinovich, D. (1972). Isr. J. Chem. 10, 537-558.

Huang, H. H. (1976). Aust. J. Chem. 29, 2415-2422.

KAFTORY, M. (1983). The Chemistry of Functional Groups, edited by S. PATAI \& Z. RAPPOPORT, Supplement D, ch. 24, pp. 1229-1263. New York: Wiley-Interscience.

LeE, J. \& NyBURG, S. C. (1985). Acta Cryst. C41, 560-567.
MCIntosh, A. O., Robertson, J. M. \& VAND, V. (1954). J. Chem. Soc. pp. 1661-1668.

Molins, E. \& Miravitlles, C. (1990). In preparation.

NybuRG, S. C. (1974). Acta Cryst. B30, 251-253.

Prelog, V. \& Helmchen, G. (1982). Angew'. Chem. Int. Ed. Engl. 21, 567-583.

Sadrai, M., Bird, G. R., Potenza, J. A. \& Schugar, H. J. (1990). Acta Cryst. C46, 637-640.

SANDSTRÖM, J. (1983). Top. Stereochem. 14, 83-181.

Shoham, G., Cohen, S., Suissa, R. M. \& Agranat, I. (1988). Molecular Structure, Chemical Reactivity and Biological Activity, edited by J. J. Stezowski, J.-L. Huang \& M.-C. ShaO, pp. 291-312. Oxford Univ. Press.

Solans, X., Miravitlles, C., DeclercQ, J.-P. \& Germain, G. (1980). Acta Cryst. B36, 2677-2683.

StaAb, H. A. \& Saupe, T. (1988). Angew. Chem. Int. Ed. Engl. 27, $865-879$.

StaAb, H. A., Saupe, T. \& Krieger, C. (1983). Angen'. Chem. Int. Ed. Engl. 22, 731-732.

Stezowski, J. J., Hildenbrand, T., Suissa, M. R. \& Agranat, I. (1989). Struct. Chem. 1, 123-126.

Acta Cryst. (1991). B47, 298-303

\title{
Deformation-Density Studies of Thiathiophthenes. II. 2,4-Diphenyl-6a-thiathiophthene
}

\author{
By Yu Wang, * S. K. Yeh, S. Y. Wu, C. T. PaI, C. R. Lee and K. J. Lin \\ Department of Chemistry, National Taiwan University, Taipei, Taiwan
}

(Received 16 July 1990; accepted 12 November 1990)

\begin{abstract}
A multipole model deformation-density study of 2,4diphenylthiathiophthene is described. Like other thiathiophthene derivatives, the title compound contains two fused five-membered rings with a linear S-S-S part. However, it has two significantly different $S-S$ distances [2.2125 (4) and 2.5087 (4) $\AA$ ], in contrast to its 2,5-dimethyl derivative, which has been shown previously to have $C_{s}$ molecular symmetry and hence two equal $S-S$ distances [2.3510 (1) $\AA$ ]. A comparison of the two derivatives is presented in terms of the multipole model deformation-density distribution. The net atomic charge of each atom obtained from the multipole refinements as well as from extended Hückel molecular orbital calculations is compared. The central S atom is more electron deficient than the other $\mathrm{S}$ atoms. Positive deformation densities are found along the $\mathrm{C}-\mathrm{C}, \mathrm{C}-\mathrm{H}$ and $\mathrm{C}-\mathrm{S}$ bonds. Small densities are found along the $\mathrm{S}-\mathrm{S}$ bonds. In general, the multipole model density distributions give much clearer features than the experimental ones. Up to
\end{abstract}

* To whom all correspondence should be addressed.

0108-7681/91/020298-06\$03.00 hexadecapole terms are needed for $\mathrm{S}$ atoms in the multipole model refinements. The $\mathrm{S}$ atom further from the central $\mathrm{S}$ atom has a higher electron density than the nearer one. This is in agreement with the three-centre four-electron bond model.

\section{Introduction}

6a-Thiathiophthene derivatives have attracted considerable interest because of the unusual type of $S-S$ bonding in these molecules (Hansen, Hordvik \& Saethre, 1975; Gleiter \& Cygax, 1976). The effect of alkyl substitution on the $\mathrm{S}-\mathrm{S}$ bond length has been discussed at great length (Hordvik \& Saethre, 1972; Wei, Paul, Beer \& Naylor, 1975; Johnson, Llaguno \& Paul, 1976; Wang, Chen \& Wu, 1988; Wang, Wu \& Cheng, 1990). Solid- and gas-state ESCA studies (Clark, Kilcast \& Reid, 1971; Saethre, Svensson, Martensson, Gelius, Malmquist, Basilier \& Siegbahn, 1977) were performed to try to solve the question of symmetry, i.e. whether the potentialenergy curve for the $\mathrm{S}-\mathrm{S}-\mathrm{S}$ system has a single or double minimum. Several empirical and nonempirical calculations on the electronic structures of (C) 1991 International Union of Crystallography 
such thiathiophthene derivatives were performed (Gleiter \& Hoffman, 1968; Palmer \& Findlay, 1974) to analyze the bond energy and the ground-state wavefunctions. Although the results show that there are two types of $\mathrm{S}-\mathrm{S}$ bond in thiathiophthene derivatives, a symmetric and an unsymmetric $\mathbf{S}-\mathbf{S}-\mathbf{S}$ part in the ground state, the fast equilibrium between two unsymmetric forms could yield a symmetric form, which could not be ruled out completely

In order to compare these two types of bonds, a charge density distribution study was performed on both types of compound to see whether there is any charge distribution difference between the two. We have chosen the compound which contains the two most different $\mathrm{S}-\mathrm{S}$ bond lengths, 2,4-diphenylthiathiophthene (1) and another which contains two identical $\mathrm{S}-\mathrm{S}$ bond lengths, 2,5-dimethylthiathiophthene (2). The experimental deformation-density studies have been published previously (Wang, Chen \& Wu, 1988; Wang, Wu \& Cheng, 1990). It is hard to compare the experimental maps because of the high noise levels in the maps. However, the situation is much improved by making multipole model deformation-density maps (Hansen \& Coppens, 1978) where all the random experimental error is suppressed. This has been illustrated previously for compound (2) (Wang, Wu \& Cheng, 1990). Therefore, the comparison between the two types of bonds will be based mainly on the multipole model density distribution.

\section{Experimental}

The low-temperature diffraction data of 2,4diphenylthiathiophthene (1) and 2,5-dimethylthiathiophthene (2) have been described previously (Wang, Chen \& Wu, 1988; Wang, Wu \& Cheng, 1990). The multipole model refinements were carried out on compound (1) in a similar way to that of compound (2) (Wang, Wu \& Cheng, 1990), with a multipole expansion of the valence shell in terms of a spherical harmonic series (Hansen \& Coppens, 1978). The expansion included up to hexadecapoles for $\mathrm{S}$ atoms, up to octapoles for $\mathrm{C}$ atoms and up to dipoles for $\mathrm{H}$ atoms. However, all the $\mathrm{C}$ and $\mathrm{H}$ atoms of each phenyl group were constrained, i.e. $\mathrm{C}(7)-\mathrm{C}(11)$ were constrained to $C(6), C(13)-C(17)$ were constrained to $\mathrm{C}(12)$. $\mathrm{H}$ atoms of the phenyl ring were constrained accordingly. Hartree-Fock functions were used for the monopoles of all the atoms. Atomic scattering amplitudes of both core and valence electrons were taken from International Tables for X-ray Crystallography (1968, Vol. III). The valence electronic configurations of $\mathrm{S}, \mathrm{C}$ and $\mathrm{H}$ are $s^{2} p^{4}, s^{2} p^{2}$ and $s^{1}$ respectively. The coefficients of all the multipole terms as well as $\kappa$ values of the $S$ and $\mathrm{C}$ atoms were included in a full-matrix refinement with the atomic parameters of non- $\mathrm{H}$ atoms. Full-matrix least-squares refinement was carried out using 7977 reflections, with multipole terms included gradually. Up to monopole refinement is comparable to conventional methods, except for the allowance of charged atoms. Up to hexadecapole refinement was tried for all the non- $\mathrm{H}$ atoms and the results are compared in Table 2 . The atomic parameters were chosen from the method described above (octapole + ). The deformation density maps were generated by subtracting the spherical atomic density from the calculated atomic density in terms of multipole expansion. All the computations were carried out on a local MicroVAX using the MOLLY program (Hansen \& Coppens, 1978) and a locally developed contour plotting program (Tsai, 1982). The extended Hückel calculation was performed using ICON (Howell, Rossi, Wallace, Haraki \& Hoffmann, 1977) and MOPLOT (Lichtenberger \& Fenske, 1975).

\section{Results}

A least-squares refinement minimizing the quantity $\sum w\left|F_{o}-S_{c} F_{c}\right|^{2}$ was performed on $100 \mathrm{~K} \mathrm{X}$-ray diffraction data (Wang, Chen \& Wu, 1988) including the atomic parameters as well as the coefficients of multipole terms. An extinction correction was not applied because no obvious effect was found on the intensities. The atomic parameters for non- $\mathrm{H}$ atoms are given in Table 1. The choice of local Cartesian axes for the multipole terms is shown in Fig. 1. The model deformation-density maps are defined as

$$
\rho=\sum_{i} \rho_{i M}(r)-\sum_{i} \rho_{i A}(r)
$$

where

$$
\begin{aligned}
\rho_{M}(r)= & P_{c} \rho_{\text {core }}(r)+P_{v} \rho_{\text {val }}(\kappa r) \\
& +\sum_{l=0}^{4} R_{l}(r) \sum_{m=-l}^{l} P_{l m} Y_{l m}(\theta, \varphi) \\
R_{l}(r)= & N r^{n_{l}} \exp (-\zeta r) .
\end{aligned}
$$

All the $\kappa$ values and $P_{l m}$ 's have been deposited.* The agreement indices for the various refinements are listed in Table 2. The parameters from the octapole + refinements are taken from the deformationdensity study. The model deformation-density maps of 2,4-diphenylthiathiophthene (1) are shown in Fig. 2 . The density distribution is in good agreement with

\footnotetext{
* Lists of $\mathrm{H}$-atom parameters, anisotropic temperature factors for non-H atoms, multipole coefficients of all the atoms, and structure factors after multipole refinement have been deposited with the British Library Document Supply Centre as Supplementary Publication No. SUP 53710 (34 pp.). Copies may be obtained through The Technical Editor, International Union of Crystallography, 5 Abbey Square, Chester $\mathrm{CH} 12 \mathrm{HU}$, England.
} 
Table 1. Atomic parameters and $B_{\mathrm{eq}}$ values $\left(\AA^{2}\right)$ (e.s.d.'s refer to the last digit printed)

\begin{tabular}{|c|c|c|c|}
\hline \multicolumn{4}{|c|}{$B_{\mathrm{eq}}=\frac{8}{3} \pi^{2} \sum_{i} \sum_{j} U_{i j} a_{i}^{*} a_{j}^{*} \mathbf{a}_{i} \cdot \mathbf{a}_{l}}$. \\
\hline$x$ & $y$ & $z$ & $B_{\mathrm{eq}}$ \\
\hline $0.32935(2)$ & $0.40612(2)$ & $0 \cdot 23883(2)$ & $1.58(1)$ \\
\hline 0.12967 (1) & $0.31705(2)$ & $0.41983(2)$ & $1.43(1)$ \\
\hline$-0.04463(2)$ & $0.24283(2)$ & $0.58347(2)$ & 1.81 (1) \\
\hline $0.38069(6)$ & $0.57569(8)$ & $0.38412(7)$ & $1 \cdot 18(2)$ \\
\hline $0.30491(7)$ & $0.59868(8)$ & 0.53091 (7) & $1 \cdot 19(2)$ \\
\hline $0 \cdot 18907(6)$ & $0.48869(8)$ & $0.56590(7)$ & $1 \cdot 16(2)$ \\
\hline $0.11280(7)$ & $0.51434(8)$ & $0.71883(8)$ & $1 \cdot 22(2)$ \\
\hline$-0.00278(8)$ & $0.40397(9)$ & $0.73846(9)$ & $1.60(2)$ \\
\hline $0.50161(5)$ & $0.69793(6)$ & $0.35618(6)$ & $1 \cdot 19(2)$ \\
\hline $0.57177(5)$ & $0.79643(7)$ & $0.47398(6)$ & $1.52(2)$ \\
\hline $0.68223(5)$ & $0.91544(7)$ & $0.44906(7)$ & $1.81(2)$ \\
\hline $0.72480(6)$ & $0.93758(7)$ & $0.30685(7)$ & $1.91(2)$ \\
\hline $0.65771(6)$ & $0.83771(8)$ & $0.18830(7)$ & $2 \cdot 13(2)$ \\
\hline $0.54714(6)$ & $0.71819(7)$ & $0.21251(6)$ & $1.73(2)$ \\
\hline $0.15525(6)$ & $0.65564(6)$ & $0.85222(6)$ & $1 \cdot 21(2)$ \\
\hline $0.06149(5)$ & $0.76928(7)$ & $0.95470(6)$ & $1.58(2)$ \\
\hline $0 \cdot 10120(6)$ & $0.90120(7)$ & $1 \cdot 08051(6)$ & $1.89(2)$ \\
\hline 0.23421 & $0.92151(7)$ & $1 \cdot 10496(6)$ & $1.83(2)$ \\
\hline $0.32807(6)$ & $0.80873(7)$ & 1.00353 & $1.85(2)$ \\
\hline $0.28866(6)$ & $0.67559(7)$ & $0.87885(6)$ & $1.56(2)$ \\
\hline
\end{tabular}

Table 2. Least-squares results of multipole refinements

$R_{1}=\sum\left|F_{o}-k F_{c} / \sum F_{o} ; \quad R_{1 w}=\left(\sum w \mid F_{o}-k F_{c}{ }^{2} / \sum w F_{o}^{2}\right)^{12} ; \quad R_{2}=\sum\right| F_{o}^{2}$ $-k F_{c}^{2} \mid / \sum F_{o}^{2} ; \quad R_{2 w}=\left(\sum w\left|F_{o}^{2}-k F_{c}^{2}\right|^{2} / \sum w F_{o}^{4}\right)^{12} ; \quad S=\left(\sum w \mid F_{o}-\right.$ $\left.\left.k F_{c}\right|^{2} / \mathrm{NO}-\mathrm{NV}\right)^{1 \cdot 2} ; \mathrm{NO}=$ number of reflections; $\mathrm{NV}=$ number of variables.

$\begin{array}{lcccccc} & \text { NV } & R_{1} & R_{1 w} & R_{2} & R_{2 w} & S \\ \text { Conventional } & 181 & 0.0441 & 0.0457 & 0.0551 & 0.0533 & 4.0810 \\ \text { Monopole } & 197 & 0.0375 & 0.0340 & 0.0451 & 0.0425 & 3.0374 \\ \text { Octapole } & 359 & 0.0271 & 0.0200 & 0.0324 & 0.0311 & 1.8045 \\ \text { Octapole + } & 386 & 0.0269 & 0.0198 & 0.0323 & 0.0309 & 1.7926 \\ \text { Hexadecapole } & 449 & 0.0268 & 0.0194 & 0.0320 & 0.0305 & 1.7597\end{array}$

* Up to hexadecapole terms for the $\mathrm{S}$ atom only.

the experimental one (Wang, Chen $\& \mathrm{Wu}, 1988$ ) but the signal-to-noise level is significantly improved in the model density map, especially in the perpendicular plane around the $\mathbf{S}$ atoms (Figs. $2 b-d$ ). Thus it is easy to make a comparison of the two compounds, one with symmetric $\mathrm{S}-\mathrm{S}$ bonds, 2,5-dimethylthiathiophthene (2) (Wang, Wu \& Cheng, 1990), and the other with unsymmetric $\mathrm{S}-\mathrm{S}$ bonds, compound (1).

Extended Hückel molecular orbital (EHMO) calculations were performed for both compounds in order to compare the theoretically calculated deformation densities. A comparison was also carried out on the model versus the theoretically calculated deformation. The theoretical deformation-density maps are depicted in Figs. 3 and 4 for compounds (1) and (2), respectively, based on the EHMO calculations with the basis set given earlier (Gleiter \& Hoffman, 1968).

\section{Discussion}

It is obvious that the model deformation density has much clearer features than the experimental density (Wang, Chen \& Wu, 1988). Only under such circum- stances can a comparison of the density maps of the different compounds be made. The model deformation densities along all the $\mathrm{C}-\mathrm{C}, \mathrm{C}-\mathrm{H}$ and $\mathrm{S}-\mathrm{C}$ bonds (see Fig. 2a) are almost the same as the experimental ones [Fig. 2 in Wang, Chen \& Wu (1988)]. However, along the $\mathrm{S}-\mathrm{S}$ region, there is less density in the model deformation-density map. The large negative feature near $\mathrm{S}$ nuclei also disappeared in the model density map. Considering the electron density of the S-S-S region in terms of $\sigma$ - and $\pi$-electron densities, the $\pi$-electron density is predominantly located at the central $\mathrm{S}$ atom, $\mathrm{S}(2)$, and the terminal $\mathrm{S}$ atoms, $\mathrm{S}(1)$ and $\mathrm{S}(3)$, have both $\sigma$ and $\pi$-electron densities. Although there is not much difference between the model deformation densities around the two terminal $\mathbf{S}$ atoms, it is conceivable that $\mathrm{S}(1)$, which has a longer $\mathrm{S}-\mathrm{S}$ bond length to the central $\mathrm{S}$ atom, $\mathrm{S}(2)$, has more $\sigma$-electron density than $S(3)$. This seems to be in agreement with earlier theoretical predictions (Gleiter \& Hoffman, 1968; Becker, Cohen-Addad, Delly, Hirshfeld \& Lehmann, 1986).

The model deformation-density distributions of compounds (1) and (2) [Fig. $3 a$ in Wang, Wu \& Cheng (1990)] are quite similar for the ring planes for

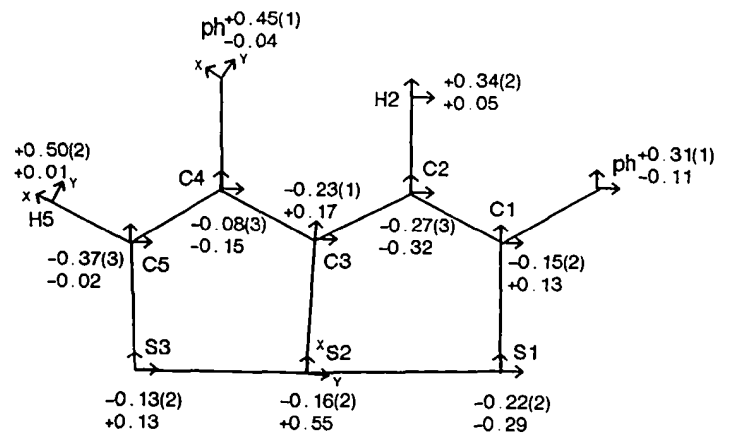

(a)

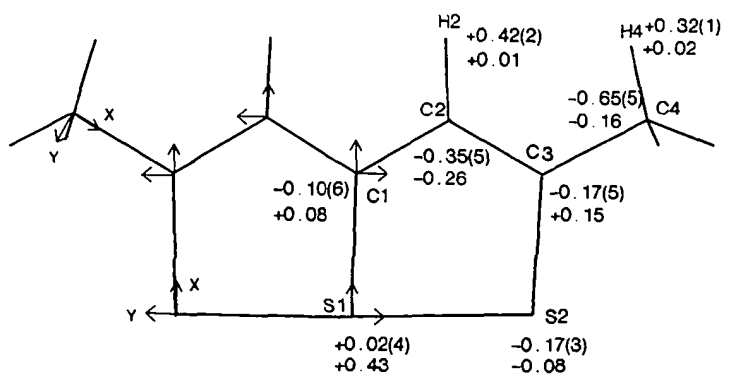

(b)

Fig. 1. Choice of local Cartesian coordinates in the multipole model and the net atomic charge of (a) 2,4-diphenylthiathiophthene, the charges shown next to $\mathrm{Ph}$ are the sum over the phenyl ring; (b) 2,5-dimethylthiathiophthene, the charges of all the $\mathbf{H}$ atoms in the methyl group are set to be the same. The value given above is for the multipole model and the value below is for the EHMO calculation. 
all the $\mathrm{C}-\mathrm{C}, \mathrm{C}-\mathrm{H}$ and $\mathrm{S}-\mathrm{C}$ bonds. Since compound (2) belongs to point group $C_{s}$, the densities around the two terminal $\mathrm{S}$ atoms are exactly the same and are similar to that around $\mathrm{S}(3)$ of compound (1) in terms of $\sigma$-electron density. However, comparing the $\pi$-electron densities, the terminal $\mathrm{S}$ atoms of compound (2) [Fig. $3 c$ in Wang, Wu \&

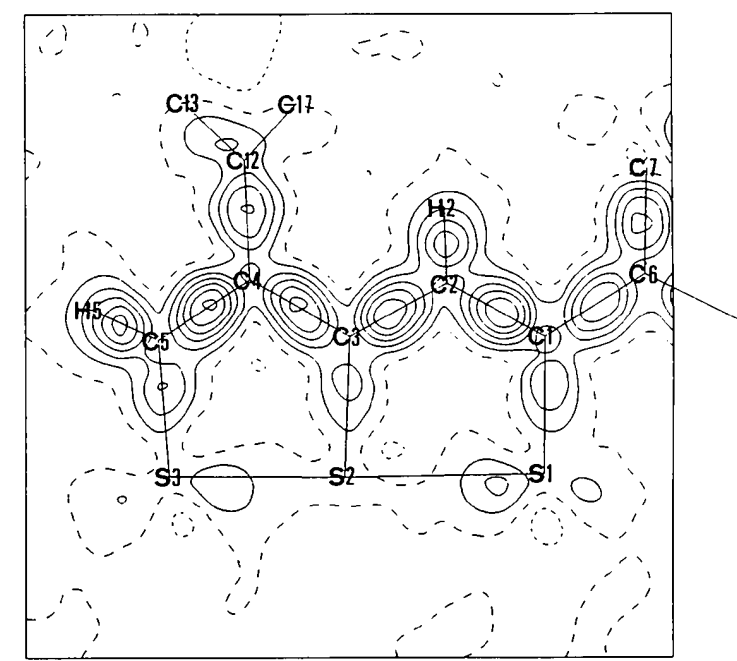

(a)

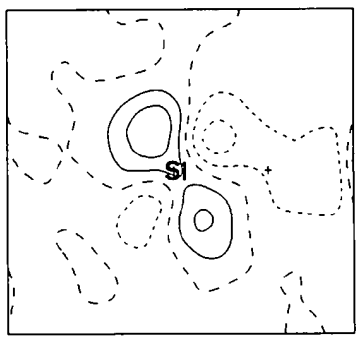

(b)

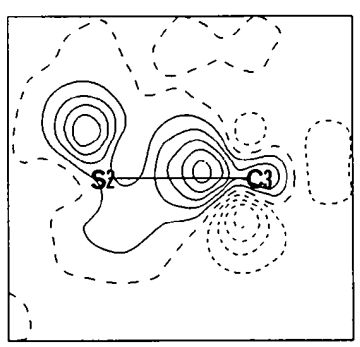

(c)

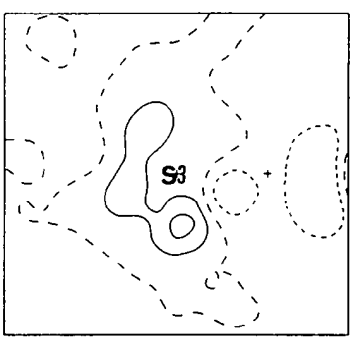

(d)

Fig. 2. Model deformation-density maps. Solid lines denote positive contours, dashed and dotted lines represent zero and negative contours. The standard deviation of the map is $0.08 \mathrm{e} \AA^{-3}$. (a) The thiathiophthene plane, contour interval $0.1 \mathrm{e} \AA^{-3}$. (b) The plane perpendicular to $(a)$ and bisecting the $\mathrm{C}(1)-\mathrm{S}(1)-\mathrm{S}(2)$ angle; the + is the projection of $\mathrm{C}(1)$, the vertical up direction is above the thiathiophthene plane; contour interval $0.05 \mathrm{e} \AA^{-3}$. (c) Plane perpendicular to $(a)$ and including $\mathrm{C}(3)-\mathrm{S}(2)$; vertical axis and contour as in $(b)$. (d) Same as $(b)$, but bisection of the $\mathrm{C}(5)-\mathrm{S}(3)-\mathrm{S}(2)$ angle; the + is the projection of $\mathrm{C}(5)$, vertical axis and contour as in $(b)$.
Cheng (1990)] have more $\pi$ density than those of compound (1) (see Figs. $2 b$ and $2 d$ ).

The deformation-density maps obtained using EHMO calculations (Fig. 3) are qualitatively in agreement with those in Fig. 2 for the $\mathrm{C}-\mathrm{C}, \mathrm{C}-\mathrm{H}$, $\mathrm{S}-\mathrm{C}$ bonds, only with less positive density along the bonds. However, there are much stronger lone-pair electron densities predominantly in the $\pi$ direction near the $\mathrm{S}$ atoms than those observed in the model density (Fig. 2). Comparing the $\pi$-electron densities of the three $\mathrm{S}$ atoms (Figs. $2 b-d$ ), there is not much difference between the three; however, $S(1)$ seems to have more diffuse electron density and thus has more density at the molecular plane along the $S(1)-S(2)$ and $\mathrm{S}(1)-\mathrm{C}(1)$ directions. Whether this could be called $\sigma$-electron density is questionable. However, as for the total electron densities around the $\mathrm{S}$ atoms, there is a slight tendency for the order $\mathrm{S}(1)>\mathrm{S}(3)>$

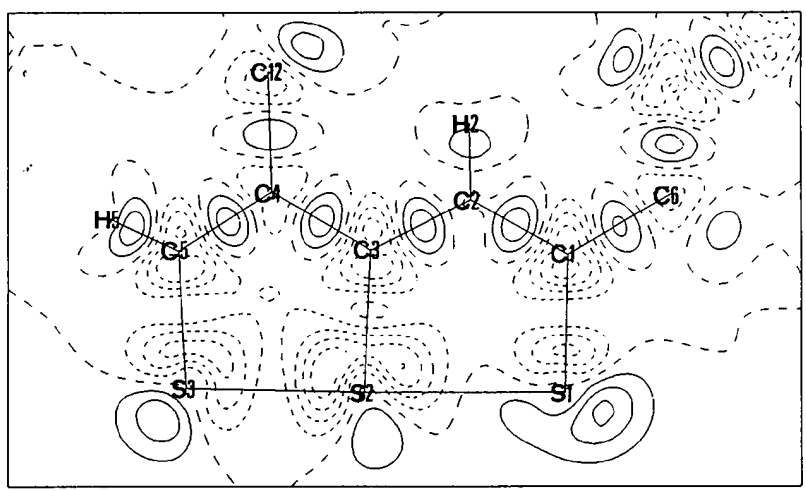

(a)

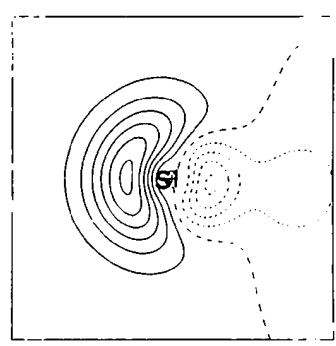

(b)

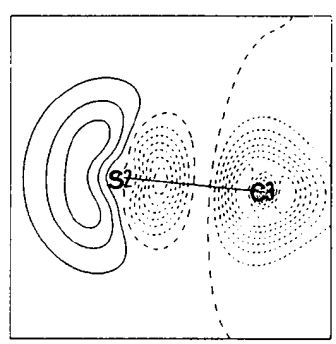

(c)

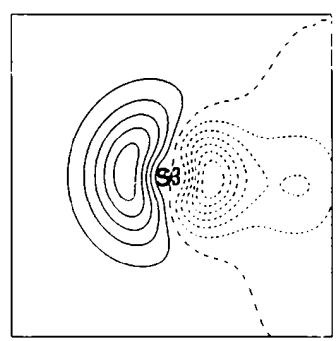

(d)

Fig. 3. Theoretical deformation-density map of compound (1) based on EHMO calculations, $(a),(b),(c)$ and $(d)$ are defined as in Fig. 2. 
$\mathrm{S}(2)$. This again gives the relationship that the greater the electron density of the $\mathrm{S}$ atom, the longer the $\mathrm{S}-\mathrm{S}$ bond is. It indicates that the three-centre four-electron bond concept is in accord with experimental observation.

Figs. 3 and 4 are both theoretically calculated deformation maps of an unsymmetric and a symmetric $\mathrm{S}-\mathrm{S}-\mathrm{S}$ system using the same basis functions. The symmetric system (Fig. 4) seems to have slightly less electron density around the $\mathrm{S}$ atoms. Obviously, the extended Hückel calculations cannot represent a good characteristic density distribution for $\mathrm{S}$ atoms, thus a more sophisticated calculation is under investigation.

The net atomic charges derived from the multipole refinement and from EHMO calculations are compared in Fig. 1(a). S(3) and $\mathrm{S}(2)$ bear similar negative charges, whereas $S(1)$ bears more negative charge than $\mathrm{S}(2)$ and $\mathrm{S}(3)$. All the $\mathrm{C}$ atoms in the ring are also negatively charged; the $\mathrm{C}$ atoms at the $2,4-$ positions are less negatively charged because of the substituted phenyl groups. The relative charge distributions obtained from the multipole refinement are in agreement with the calculated values (EHMO), but the calculated values show more pronounced alternation. It is interesting to compare the net charge distributions of compounds (1) and (2) shown in Figs. $1(a)$ and $1(b)$. In compound (2), the central S

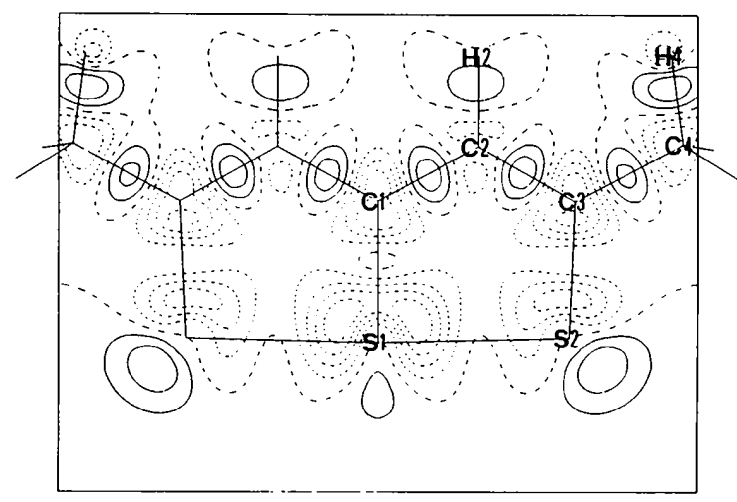

(a)

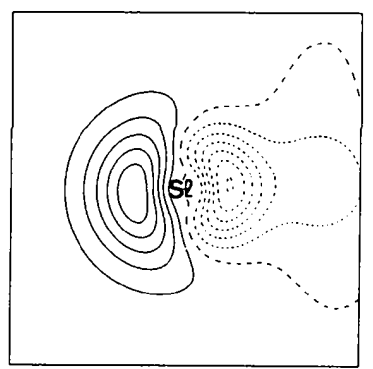

(b)

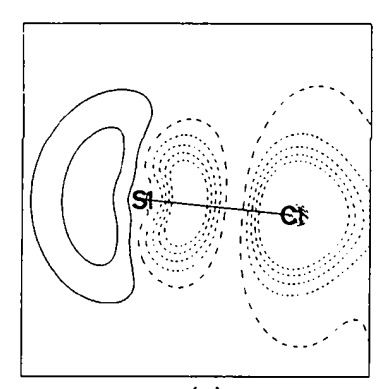

(c)
Fig. 4. Theoretical deformation-density map of compound (2) based on EHMO calculations, $(a),(b)$ and $(c)$ are defined as in Fig. 2. atom is neutral. Actually, chemical reactions have been reported (Christie, Ingram \& Reid, 1974; Ingold, Reid \& Walton, 1982) where the electrophilic attack was found on the terminal $\mathrm{S}$ atom or on the 3-position of the thiathiophthene ring, $\mathrm{C}(2)$, which were also found to be most negatively charged in this work. Recently, a theoretical calculation concerning the relationship between $\mathrm{S}-\mathrm{S}$ bond length and the electron density, $\rho(r c)$, at the critical points in the bond has been reported (Knop, Boyd \& Choi, 1988), where a power law $d(\mathbf{S}-\mathbf{S})=1 \cdot 229[\rho(r c)]^{-0.269}$ was proposed. That is, the longer the $\mathrm{S}-\mathrm{S}$ bond, the less bonding electron density there will be between the bonded atoms. This is true in the case of thiathiophthene where the $\mathrm{S}-\mathrm{S}$ bond lengths are longer than all the normal $\mathrm{S}-\mathrm{S}$ single-bond lengths quoted in the literature. Little density accumulation was found in either compounds (1) or (2). In conclusion, in a symmetric $\mathrm{S}-\mathrm{S}-\mathrm{S}$ system, the central $\mathrm{S}$ atom is certainly in a hypervalent state or an electron deficient centre, as in 2,5-diaza-1,6-dioxa-6athiapentalene (Fabius, Cohen-Addad, Larsen, Lehmann \& Becker, 1989), while the terminal S atoms are electron rich and are favourable for an electrophilic attack. In an unsymmetric $\mathrm{S}-\mathrm{S}-\mathrm{S}$ system, the terminal $\mathrm{S}$ atom with the longer $\mathrm{S}-\mathrm{S}$ length is more negatively charged than the $S$ atom with the shorter $\mathrm{S}-\mathrm{S}$ length and is the site preferred for electrophilic attack.

\section{References}

Becker, P., Cohen-Addad, C., Delley, B., Hirshfeld, F. L. \& Lehmann, M. S. (1986). Applied Quantum Chemistry, edited by V. H. Smith JR, H. F. Schaefer III \& K. Morokuma, pp. 361-373. Dordrecht: D. Reidel.

Christie, R. M., Ingram, A. S. \& Reid, D. H. (1974). J. Chem. Soc. Perkin Trans. 1, pp. 722-728.

Clark, D. T., Kilcast, D. \& Reid, D. H. (1971). J. Chem. Soc. Chem. Commun. pp. 638-639.

Fabius, B., Cohen-Addad, C., Larsen, F. K., Lehmann, M. S. \& Becker, P. (1989). J. Am. Chem. Soc. 111, 5728-5732.

Gleiter, R. \& CygaX, R. (1976). Top. Curr. Chem. 63, 49-88.

Gleiter, R. \& Hoffmann, R. (1968). Tetrahedron, 24, 5899-5911.

Hansen, N. H. \& Coppens, P. (1978). Acta Cryst. A34, 909-921.

Hansen, L. K., Hordvik, A. \& Saethre, L. J. (1975). Organic Sulfur Chemistry, edited by C. J. M. STIRLING. London: Butterworths.

Hordvik, A. \& Saethre, L. J. (1972). Acta Chem. Scand. 26, 3114-3130.

Howell, J., Rossi, A., Wallace, D., Haraki, K. \& Hoffmann, R. (1977). ICON. Program for extended Hückel molecular orbital calculations. Quantum Chemistry Program Exchange, Univ. of Indiana, USA.

Ingold, K. U., Reid, D. H. \& Walton, J. C. (1982). J. Chem. Soc. Perkin Trans. 2, pp. 431-436.

Johnson, P. L., Llaguno, E. C. \& Paul, I. C. (1976). J. Chem. Soc. Perkin Trans. 2, pp. 234-238.

Knop, O., Boyd, R. J. \& Chol, S. C. (1988). J. Am. Chem. Soc. 110, 7299-7301.

LiCHTENBERger, D. L. \& FENSKe, R. F. (1975). MOPLOT. Quantum Chemistry Program Exchange, Univ. of Indiana, USA. 
Palmer, M. H. \& Findlay, R. H. (1974). J. Chem. Soc. Perkin Trans. 2, pp. 1885-1893.

Saethre, L. J., Svensson, S., Martensson, N., Gelius, U., Malmquist, P. A., Basilier, E. \& Siegbahn, K. (1977). Chem. Phys. 20, 431-436.

TsaI, C. J. (1982). Msc Thesis, National Taiwan Univ., Taiwan.
Wang, Y., Chen, M. J. \& Wu, C. H. (1988). Acta Cryst. B44, 179-182.

Wang, Y., Wu, S. Y. \& Cheng, A. C. (1990). Acta Cryst. B46, 850-854.

Wei, K., Paul, I. C., Beer, R. J. S. \& Naylor, A. (1975). J. Chem. Soc. Chem. Commun. pp. 264-265. 